\title{
Optimal use of smoking cessation pharmacotherapy
}

Colin Mendelsohn (D)

General practice, Double Bay, Sydney

\section{Keywords}

bupropion, nicotine replacement therapy, varenicline

Aust Prescr 2022;45:10-14 https://doi.org/10.18773/ austprescr.2022.001 smoking cessation, vaping,

\section{SUMMARY}

The most effective intervention for stopping smoking is a combination of professional counselling and pharmacotherapy. Medicines are recommended for all smokers who are motivated to quit and are nicotine dependent.

Combination nicotine replacement therapy with a patch and an oral product is more effective than the patch alone. An adequate dose of nicotine must be used for an adequate duration.

Varenicline is the most effective oral drug. It is safe in people with stable mental illness.

Vaping nicotine is a second-line treatment which can be considered for smokers who are unable to quit with other methods.

\section{Introduction}

Tobacco smoking remains Australia's leading preventable cause of death and illness, prematurely killing 21,000 people every year. ${ }^{1}$ At any time, two in three smokers intend to quit. ${ }^{2}$ Brief interventions by GPs can significantly increase quit rates. ${ }^{3}$ The most effective intervention is professional support combined with pharmacotherapy. ${ }^{4}$

\section{Assessment}

All smokers should be offered a brief intervention, such as Ask-Advise-Help. This involves asking all patients if they smoke, advising all smokers to quit and offering treatment or referral. ${ }^{4}$ If time allows, more detailed support can be given and follow-up

\section{Table 1 Heaviness of Smoking Index for assessing} nicotine dependence

\begin{tabular}{ll|l}
\hline Criterion & Scoring & Score \\
\hline Average cigarettes per day & $1-10=0$ points & \\
& $11-20=1$ point & \\
& $21-30=2$ points & \\
& $\geq 31=3$ points & \\
Time to first cigarettes (minutes) & $61+=0$ points & \\
& $31-60=1$ point & \\
$5-30=2$ points & \\
& $<5=3$ points & \\
\hline
\end{tabular}

visits arranged. Smokers who are ambivalent about quitting may benefit from motivational interviewing. ${ }^{5}$ Pharmacotherapy is indicated for all smokers who are motivated to quit and are nicotine dependent. ${ }^{4}$ Their dependence on nicotine can be assessed using the Heaviness of Smoking Index (Table 1). ${ }^{6}$ The sooner a patient smokes after waking and the more cigarettes smoked daily, the more benefit is generally expected from pharmacotherapy?

Some smokers are driven more by the smoking ritual and behavioural triggers and less by nicotine dependence. These smokers may benefit from behavioural counselling or vaping, with or without nicotine. ${ }^{8}$

\section{Pharmacotherapy}

Table 2 shows the increase in smoking cessation with first- and second-line drugs compared to control interventions or placebo in systematic reviews of randomised controlled trials..$^{9-11}$ All treatments are more effective with behavioural support. ${ }^{12}$

Drugs only have a modest effect on quit rates so it is important to have realistic expectations of treatment. The key to long-term success is to keep trying to quit at every opportunity. For the best health outcomes, the most effective treatment should be used as soon as possible.

If a previous pharmacotherapy was effective and well tolerated, it is generally best to use the same drug again. Other factors guiding the choice of drug include effectiveness, personal preferences, contraindications, drug interactions and cost. Varenicline, bupropion, nicotine patches, gum and lozenges are all available on the Pharmaceutical Benefits Scheme. However, only one product is subsidised at a time. 
Table 2 Efficacy of pharmacotherapy for smoking cessation at 6-12 months

\begin{tabular}{|c|c|c|}
\hline Drug & Effect size* & Quality of the evidence (grade) \\
\hline \multicolumn{3}{|l|}{ Comparison to control or placebo } \\
\hline Varenicline $^{9}$ & $15 \%$ & High \\
\hline Combination nicotine replacement therapy ${ }^{9}$ & $11 \%$ & High \\
\hline Bupropion ${ }^{9}$ & $7 \%$ & High \\
\hline Single nicotine replacement therapy ${ }^{9}$ & $6 \%$ & High \\
\hline
\end{tabular}

Comparison to nicotine replacement therapy

\begin{tabular}{lll}
\hline Vaping nicotine $^{10}$ & $3 \%$ & Moderate \\
Varenicline $^{11}$ & $4.8 \%$ & Moderate \\
\hline
\end{tabular}

* Effect size is the increase in the efficacy of the drug compared to the comparator

\section{Nicotine replacement therapy}

Nicotine replacement therapy is the most widely used first-line treatment. It is approved for use by people from the age of 12 years. Nicotine replacement therapy temporarily replaces the nicotine from smoking, reducing cravings and withdrawal symptoms. The nicotine is delivered more slowly than from smoking and monotherapy generally achieves blood concentrations around half those of smoking. ${ }^{13}$ Two types of nicotine replacement therapy are available:

- The nicotine patch releases nicotine steadily through the day and relieves background cravings. ${ }^{13}$

- Oral preparations act more quickly but are shorter acting..$^{13}$ The gum, lozenge and inhalator are best used regularly, say hourly, or 20 minutes before a trigger is anticipated, such as before eating. The mouth spray starts to work within about a minute and can help manage unexpected cravings.

\section{Optimising nicotine replacement therapy}

As nicotine replacement therapy combined with counselling only has a modest effect on quit rates, it is important to optimise its use to increase the chance of success.

\section{Combination nicotine replacement therapy}

Combining the nicotine patch with an oral form of nicotine replacement therapy relieves both background and breakthrough cravings. This is more effective than using a single formulation. ${ }^{14}$ Combination therapy should be considered for all smokers, especially those who are more nicotine dependent or when nicotine replacement monotherapy has not worked.

\section{Address concerns about safety}

Misinformed safety concerns are a major cause of poor adherence. ${ }^{15}$ Patients should therefore be reassured about the safety and low addictive potential of nicotine replacement therapy. Explain that nicotine does not cause cancer or lung disease and only has a minor role in cardiovascular disease. ${ }^{16}$ Nicotine replacement therapy is always safer than smoking. ${ }^{16}$

\section{Correct use of oral products}

It is important to give clear instructions on how to use oral products and to review the technique regularly, as most patients use them incorrectly. ${ }^{17}$ All oral products including the inhalator are absorbed in the buccal cavity. Instruct patients not to eat or drink for 10 minutes before use as this reduces absorption. ${ }^{18}$

Explain the 'chew and park' technique for using gum and the importance of shallow, frequent puffs from the inhalator. Lozenges should be dissolved slowly in the mouth over about 20 minutes. The mouth spray is used under the tongue and swallowing should be delayed as long as possible.

\section{Adequate dosing}

Most patients do not use enough nicotine, often due to misperceptions about safety. ${ }^{17}$ The dose should be sufficient to control withdrawal symptoms and cravings with frequent review to titrate the dose accordingly. More heavily dependent smokers should use combination nicotine replacement therapy, use $4 \mathrm{mg}$ gum or lozenges instead of $2 \mathrm{mg}$ and they may need two patches. ${ }^{17}$ Too much nicotine causes nausea, but the risk of toxicity is very low. ${ }^{19}$ 


\section{Pre-cessation patch}

Starting the nicotine patch two weeks before the day the patient intends to stop smoking increases quit rates by $25 \%$ compared to starting on the quit day. ${ }^{14}$

\section{Adequate duration}

A course of at least 10 weeks is recommended. ${ }^{4}$ At the end of the course abrupt cessation of nicotine replacement therapy is generally advised as the evidence does not support tapering. ${ }^{14}$ Extending the course for 12-18 months may help prevent relapse. ${ }^{20}$

\section{Adverse effects}

Minor adverse effects are common with nicotine replacement therapy. They vary with the method of delivery (Table 3).

\section{Precautions}

Nicotine replacement therapy is safe in stable cardiovascular disease. ${ }^{21}$ Oral nicotine replacement therapy is approved in pregnancy with informed consent if behavioural treatment has not been successful, although there is no clear evidence of effectiveness. ${ }^{4}$ Larger doses are needed as nicotine clearance is accelerated in pregnancy. Nicotine is linked to harmful effects on the fetus in animal studies, but there is no evidence so far of harm to the human fetus. Nicotine replacement therapy can also be used while breastfeeding. ${ }^{4}$ There are no relevant drug interactions with nicotine replacement therapy. As the pharmacokinetics of some drugs are affected by smoking, check if any dose adjustments are needed when quitting. ${ }^{22}$

\section{Varenicline}

Varenicline is the most effective monotherapy for smoking cessation. ${ }^{9}$ It blocks nicotine receptors in the brain and relieves cravings and withdrawal symptoms. It also reduces the reward if a cigarette is smoked.

The dose of varenicline is up-titrated over the first week. It should always be taken with food to reduce the risk of nausea. A full course of 12 weeks is recommended and a second course can be considered to prevent relapse. ${ }^{4}$

There are two ways to take varenicline:

- Flexible option - start varenicline, then quit smoking between days 8 and 35 of treatment.

- Fixed option - set a quit date and start varenicline one or two weeks before that date.

Combining varenicline and a nicotine patch significantly increases quit rates compared to varenicline alone. ${ }^{23}$ The combination is well tolerated and can be considered if monotherapy has failed.

\section{Precautions}

Adverse effects include nausea (usually selflimiting), headache, insomnia and disturbed dreams." Varenicline has no known drug interactions, but is contraindicated in pregnancy and lactation and is only approved for adults. The dose should be reduced in severe renal impairment.

Varenicline is safe and effective in people with stable mental illness. ${ }^{24}$ Although many patients are reluctant to take it because of reports of depression, behavioural changes and suicidal ideation, there is no definite evidence that varenicline causes these conditions. Everyone who quits smoking is at increased risk of psychological stress, especially those with mental illness. ${ }^{24}$ All patients who quit smoking should be advised accordingly and monitored for mood or behavioural changes. Advise them to stop varenicline and contact their doctor if there is any concern.

\section{Bupropion}

Bupropion is an antidepressant that is also an effective aid for quitting smoking. ${ }^{25}$ It is taken as an eight-week course with quitting in the second week. Adverse effects include insomnia, dry mouth and nausea. ${ }^{25}$ The main risk from bupropion is a onein-a-thousand incidence of seizures. ${ }^{26}$ Bupropion

\section{Table 3 Adverse effects of nicotine-containing products}

\begin{tabular}{lll}
\hline Product & Adverse effects & Management \\
\hline Nicotine patch & Skin irritation, redness, itch & $\begin{array}{l}\text { \% hydrocortisone } \\
\text { Rotate application site daily }\end{array}$ \\
& & Use 16-hour patch or remove the \\
& Insomnia and vivid dreams & 24-hour patch at bedtime \\
\hline Gum, inhalator, lozenge & Dyspepsia, nausea and throat irritation & Avoid swallowing excessively \\
Mouth spray & Throat irritation, hiccups & Delay swallowing \\
\hline Vaping nicotine liquid & Cough, dry throat, nausea, headache & Sips of water for dry throat \\
\hline
\end{tabular}


is contraindicated in patients with a raised seizure risk and should be used with caution in people taking drugs that can lower seizure threshold, such as antidepressants. ${ }^{26}$ Pregnancy is also a contraindication.

\section{Vaping nicotine}

For smokers who have been unable to quit with other methods, vaping is considered a second-line option. ${ }^{4}$ It is the most widely used quitting aid globally and in Australia. ${ }^{2}$ Vaping provides the nicotine that smokers crave as well as the rituals and sensations of smoking, but without most of the toxins and carcinogens from burning tobacco. The cost of vaping nicotine is about $10 \%$ of the cost of smoking on average.

The Royal Australian College of General Practitioners (RACGP) guidelines state: ${ }^{4}$

'For people who have tried to achieve smoking cessation with first-line therapy (combination of behavioural support and Therapeutic Goods Administrationapproved pharmacotherapy) but failed and are still motivated to quit smoking, nicotine vaping products may be a reasonable intervention to recommend along with behavioural support.'

Vaping can be used as a short-term quitting aid, but could have a long-term role for tobacco-harm reduction. Reviews of randomised controlled trials have found that vaping nicotine was about $50 \%$ more effective than nicotine replacement therapy. ${ }^{27,28}$ In absolute terms, six out of 100 smokers will quit with nicotine replacement therapy and 9-10 will quit with vaping nicotine. More studies are needed to confirm the exact effect size. These findings are consistent with those of observational and large population studies.

Vaping is not risk-free, but it is considerably less harmful than smoking. ${ }^{29}$ Vapour contains low doses of some toxic chemicals such as heavy metals, carbonyls and volatile organic compounds.

Some studies have associated vaping with impaired cell viability, impaired immune defences, increased inflammatory markers, oxidative stress and airways hyper-responsiveness. There is some evidence that vaping may worsen asthma and cause cough and lung irritation in non-smoking adolescents and cause school absenteeism. ${ }^{30}$ However, asthma, ${ }^{31}$ chronic obstructive pulmonary disease, ${ }^{32}$ lung function ${ }^{33}$ and respiratory symptoms ${ }^{34}$ can improve when adult smokers switch to vaping.

While the long-term risk of vaping nicotine is unknown, it is unlikely to be more than $5 \%$ of the risk of smoking, according to the Royal College of
Physicians. ${ }^{29}$ There is also no evidence of significant harm from passive exposure. ${ }^{29}$

Patients should be advised that no products are currently approved by the Therapeutic Goods Administration. Short-term use is recommended, but long-term use to prevent relapse to smoking is likely to be far less harmful than relapse to smoking. ${ }^{29}$ Continuing use of vaping and smoking (dual use) should be discouraged.

It is illegal in Australia to use nicotine liquid without a prescription, but it can be accessed by two legal pathways:

- Nicotine liquid can be dispensed by Australian pharmacies and online pharmacies with a prescription from a doctor who is an Authorised Prescriber of nicotine.

- It can also be imported from overseas under the Therapeutic Goods Administration's Personal Importation Scheme. ${ }^{35}$ Individuals can order three months supply at a time for personal use, up to a total of 15 months supply each year. Patients must arrange for a copy of their prescription to be sent to the vendor and enclosed with their order.

More information about vaping regulations is available on the Therapeutic Goods Administration website. ${ }^{36}$

\section{Conclusion}

Pharmacotherapy combined with counselling can help smokers quit. The most effective first-line treatments are varenicline and combination nicotine replacement therapy. Vaping nicotine is considered a second-line option for smokers who are unable to quit with other therapies. $\varangle$

Conflicts of interest: Colin Mendelsohn has received funding from Pfizer, GlaxoSmithKline, Johnson \& Johnson (Pacific) and Perrigo Australia for teaching, consulting and conference expenses. He is on Pfizer's Champix Advisory Board.

Dr Mendelsohn has not received any payments from electronic cigarette or tobacco companies. He has a special interest in tobacco-harm reduction and vaping nicotine and was the founding chairman of the Australian Tobacco Harm Reduction Association (ATHRA), a health promotion charity established to raise awareness of safer alternatives to smoking, but is no longer on the Board. ATHRA received funding from the vape industry to establish the charity which was publicly declared. He is the author of a self-funded book called

Stop Smoking Start Vaping. 


\section{REFERENCES}

1. Australian Institute of Health and Welfare. Burden of tobacco use in Australia: Australian Burden of Disease Study 2015. Australian Burden of Disease series no. 21. Cat. no. BOD 20. Canberra: AIHW. 2019. www.aihw.gov.au/reports/ burden-of-disease/burden-of-tobacco-use-in-australia/summary [cited 2022 Jan 4]

2. Australian Institute of Health and Welfare. National Drug Strategy Household Survey 2019. Drug Statistics series no. 32. PHE 270. Canberra: AlHW; 2020. www.aihw.gov.au/reports/illicit-use-of-drugs/national-drug-strategyhousehold-survey-2019/contents/summary [cited 2022 Jan 4]

3. Stead LF, Buitrago D, Preciado N, Sanchez G, Hartmann-Boyce J, Lancaster T. Physician advice for smoking cessation. Cochrane Database Syst Rev 2013;2013:CD000165. https://doi.org/10.1002/14651858.cd000165.pub4

4. Royal Australian College of General Practitioners. Supporting smoking cessation: a guide for health professionals. Revised 2021 Sep 29. www.racgp.org.au/clinical-resources/clinical-guidelines/key-racgp-guidelines/ view-all-racgp-guidelines/supporting-smoking-cessation [cited 2022 Jan 4]

5. Mendelsohn CP, Richmond R. GPs can help patients to stop smoking. Med J Aust 1992;157:463-7. https://doi.org/10.5694/j.1326-5377.1992.tb137309.x

6. Heatherton TF, Kozlowski LT, Frecker RC, Rickert W, Robinson J. Measuring the heaviness of smoking: using self-reported time to the first cigarette of the day and number of cigarettes smoked per day. Br J Addict 1989;84:791-800. https://doi.org/10.1111/j.1360-0443.1989.tb03059.x

7. Shiffman S, Sembower MA, Rohay JM, Gitchell JG, Garvey AJ. Assigning dose of nicotine gum by time to first cigarette. Nicotine Tob Res 2013;15:407-12. https://doi.org/10.1093/ntr/nts141

8. Notley C, Ward E, Dawkins L, Holland R. The unique contribution of e-cigarettes for tobacco harm reduction in supporting smoking relapse prevention. Harm Reduct J 2018;15:31. https://doi.org/10.1186/s12954-018-0237-7

9. Cahill K, Stevens S, Perera R, Lancaster T. Pharmacological interventions for smoking cessation: an overview and network meta-analysis. Cochrane Database Syst Rev 2013:CD009329. https://doi.org/10.1002/ 14651858.CD009329.pub2

10. Hartmann-Boyce J, McRobbie H, Lindson N, Bullen C, Begh R, Theodoulou A et al. Electronic cigarettes for smoking cessation. Cochrane Database Syst Rev 2021;4:CD010216. https://doi.org/10.1002/14651858.CD010216.pub5

11. Cahill K, Lindson-Hawley N, Thomas KH, Fanshawe TR, Lancaster T. Nicotine receptor partial agonists for smoking cessation. Cochrane Database Syst Rev 2016;(5):CD006103. https://doi.org/10.1002/14651858.CD006103.pub7

12. Stead LF, Lancaster T. Behavioural interventions as adjuncts to pharmacotherapy for smoking cessation. Cochrane Database Syst Rev 2012:12:CD009670. https://doi.org/10.1002/14651858.cd010216.pub5

13. Hukkanen J, Jacob P 3rd, Benowitz NL. Metabolism and disposition kinetics of nicotine. Pharmacol Rev 2005;57:79-115. https://doi.org/10.1124/pr.57.1.3

14. Lindson N, Chepkin SC, Ye W, Fanshawe TR, Bullen C, Hartmann-Boyce J. Different doses, durations and modes of delivery of nicotine replacement therapy for smoking cessation. Cochrane Database Syst Rev 2019;4:CD013308. https://doi.org/10.1002/14651858.CD013308

15. Ferguson SG, Schuz B, Gitchell JG. Use of smoking cessation aids: role of perceived safety and efficacy. J Smok Cessat 2012; 7:1-3. https://doi.org/ 10.1017/jsc.2012.11

16. Zwar N, Bell J, Peters M, Christie M, Mendelsohn C. Nicotine and nicotine replacement therapy - the facts. Aust Pharmacist 2006;25:969-73. http://www.e-rauchen-forum.de/uploads/nicotine.pdf [cited 2022 Jan 4]

17. Mendelsohn C. Optimising nicotine replacement therapy in clinical practice. Aust Fam Physician 2013:42:305-9.

18. Henningfield JE, Radzius A, Cooper TM, Clayton RR. Drinking coffee and carbonated beverages blocks absorption of nicotine from nicotine polacrilex gum. JAMA 1990;264:1560-4. https://doi.org/10.1001/ jama.1990.03450120072032

19. Tonstad S, Gustavsson G, Kruse E, Walmsley JM, Westin A. Symptoms of nicotine toxicity in subjects achieving high cotinine levels during nicotine replacement therapy. Nicotine Tob Res 2014;16:1266-71. https://doi.org/ 10.1093/ntr/ntu076

\section{FURTHER READING}

Australian Tobacco Harm Reduction Association. [Additional information for health professionals on vaping and prescribing nicotine] www.athra.org.au [cited 2022 Jan 4]

Mendelsohn C, Wodak A. Vaping: 10 frequently asked questions. Respir Med Today 2018;31:34-6. https://respiratory.medicinetoday.com.au/2018/june/regular-series/ vaping-10-frequently-asked-questions [cited 2022 Jan 4]
20. Agboola S, McNeill A, Coleman T, Leonardi Bee J. A systematic review of the effectiveness of smoking relapse prevention interventions for abstinent smokers. Addiction 2010;105:1362-80. https://doi.org/10.1111/j.1360-0443.2010.02996.x

21. Benowitz NL, Pipe A, West R, Hays JT, Tonstad S, McRae T, et al. Cardiovascular safety of varenicline, bupropion, and nicotine patch in smokers: a randomized clinical trial. JAMA Intern Med 2018;178:622-31. https://doi.org/10.1001/jamainternmed.2018.0397

22. Hodgson $\mathrm{G}$. What are the clinically significant drug interactions with tobacco smoking? UK Medicines Information; 2020. Available through Specialist Pharmacy Service. https://www.sps.nhs.uk/articles/what-are-the-clinicallysignificant-drug-interactions-with-tobacco-smoking [cited 2022 Jan 4]

23. Chang PH, Chiang CH, Ho WC, Wu PZ, Tsai JS, Guo FR. Combination therapy of varenicline with nicotine replacement therapy is better than varenicline alone: a systematic review and meta-analysis of randomized controlled trials. BMC Public Health 2015;15:689. https://doi.org/10.1186/s12889-015-2055-0

24. Anthenelli RM, Benowitz NL, West R, St Aubin L, McRae T, Lawrence D, et al. Neuropsychiatric safety and efficacy of varenicline, bupropion, and nicotine patch in smokers with and without psychiatric disorders (EAGLES): a doubleblind, randomised, placebo-controlled clinical trial. Lancet 2016;387:2507-20. https://doi.org/10.1016/S0140-6736(16)30272-0

25. Hughes JR, Stead LF, Hartmann-Boyce J, Cahill K, Lancaster T. Antidepressants for smoking cessation. Cochrane Database Syst Rev 2014:CD000031. https://doi.org/10.1002/14651858.cd000031.pub4

26. Therapeutic Goods Administration. Bupropion (Zyban SR). Canberra: TGA; 2001. www.tga.gov.au/alert/bupropion-zyban-sr [cited 2022 Jan 4]

27. The Joanna Briggs Institute. E-cigarettes for smoking cessation guideline update: technical report of evidence review and summary of findings. 2019. https://www.racgp.org.au/getmedia/2e90f512-a8a8-4c89-b22656ada993c7f1/ECigarettes-for-Smoking-Cessation-Technical-Report.pdf.aspx [cited 2022 Jan 4]

28. Hartmann-Boyce J, McRobbie H, Butler AR, Lindson N, Bullen C, Begh R, et al. Electronic cigarettes for smoking cessation. Cochrane Database Syst Rev 2021:CD010216. https://doi.org/10.1002/14651858.CD010216.pub6

29. Royal College of Physicians. Nicotine without smoke: tobacco harm reduction. London: RCP; 2016. https://www.rcplondon.ac.uk/projects/outputs/nicotinewithout-smoke-tobacco-harm-reduction-0 [cited 2022 Jan 4]

30. Wills TA, Soneji SS, Choi K, Jaspers I, Tam EK. E-cigarette use and respiratory disorders: an integrative review of converging evidence from epidemiological and laboratory studies. Eur Respir J 2021;57:1901815. https://doi.org/10.1183/ 13993003.01815-2019

31. Polosa R, Morjaria J, Caponnetto P, Caruso M, Strano S, Battaglia E, et al. Effect of smoking abstinence and reduction in asthmatic smokers switching to electronic cigarettes: evidence for harm reversal. Int J Environ Res Public Health 2014;11:4965-77. https://doi.org/10.3390/ijerph110504965

32. Polosa R, Morjaria JB, Prosperini U, Busà B, Pennisi A, Malerba M, et al. COPD smokers who switched to e-cigarettes: health outcomes at 5-year follow up. Ther Adv Chronic Dis 2020;11:2040622320961617. https://doi.org/10.1177/ 2040622320961617

33. Cibella F, Campagna D, Caponnetto P, Amaradio MD, Caruso M, Russo C, et al. Lung function and respiratory symptoms in a randomized smoking cessation trial of electronic cigarettes. Clin Sci (Lond) 2016;130:1929-37. Epub 2016 Aug 19. https://doi.org/10.1042/CS20160268

34. Hajek P, Phillips-Waller A, Przulj D, Pesola F, Myers Smith K, Bisal N, et al. A randomized trial of e-cigarettes versus nicotine-replacement therapy. N Engl J Med 2019;380:629-37. https://doi.org/10.1056/NEJMoa1808779

35. Department of Health, Therapeutic Goods Administration. Personal Importation Scheme. 2015 Mar 18. Canberra: Commonwealth of Australia; 2015. https://www.tga.gov.au/personal-importation-scheme [cited 2022 Jan 4]

36. Department of Health, Therapeutic Goods Administration. Nicotine vaping products: information for prescribers. 2021 Oct 27. Canberra: Commonwealth of Australia; 2021. https://www.tga.gov.au/nicotine-e-cigarettes-informationprescribers [cited 2022 Jan 4]
Royal Australian College of General Practitioners. Supporting smoking cessation: a guide for health professionals. 2021 Sep 29. Melbourne: RACGP; 2021. https://www.racgp.org.au/supporting-smoking-cessation [cited 2022 Jan 4] 